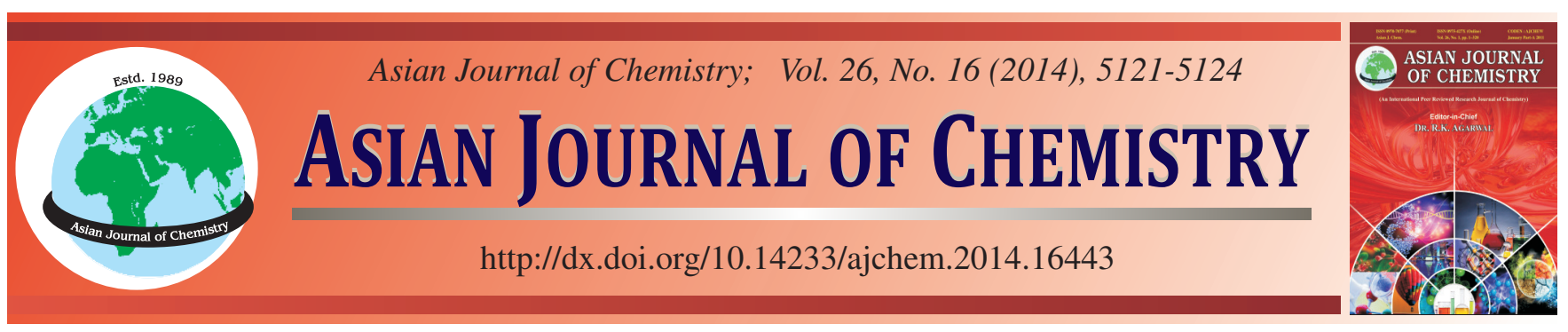

\title{
Kinetics and Mechanistic Studies of Ru(III) Catalyzed Oxidation of $p$-Hydroxy Benzoic Acid by Sodium N-chloro-p-toluene Sulphonamide in Acidic Media
}

\author{
KAMINI SINGH and R.A. SINGH*
}

Department of Chemistry, Chemical Kinetics Research Laboratory, Tilak Dhari P.G. College, Jaunpur-222 002, India

*Corresponding author: E-mail: rasinghtdc@ rediffmail.com

\begin{abstract}
Kinetics studies of the oxidation of $p$-hydroxy benzoic acid by sodium $\mathrm{N}$-chloro- $p$-toluene sulphonamide (chloramine-T or CAT) have been carried out in aqueous perchloric acid medium at $35^{\circ} \mathrm{C}$. The reaction follows almost similar kinetics, being first order with respect to chloramine-T, $p$-hydroxy benzoic acid and $\mathrm{Ru}(\mathrm{III})$. The reaction exhibits inverse first order depedence on the concentration of medium $\left[\mathrm{HClO}_{4}\right]$. Variation of ionic strength by adding $\mathrm{NaClO}_{4}$ have no significant effect on the reaction rate. The addition of $p$-toluene sulphonamide, which is one of the reaction products, had no significant effect on the reaction rate. Thermodynamic parameters were computed by studying the reactions at different temperature $(303-318 \mathrm{~K})$. The rate laws derived are in excellent agreement with the experimental results. A mechanism consistent with the above kinetic result has been suggested.
\end{abstract}

Keywords: Kinetics, Mechanism, $p$-Hydroxy banzoic acid, Chloramine-T, Oxidation, Perchloric acid, Ruthenium(III) chloride.

\section{INTRODUCTION}

The chemistry of aromatic sulphonyl haloamines has evoked considerable interest as they act as sources of halonium cations, hypohalite species and $\mathrm{N}$-anions which act both as bases and nucleophiles ${ }^{1}$. The prominent members of this group are chloramine- $\mathrm{T}$ [CAT] and chloramine- $\mathrm{B}$ [CAB] and the mechanistic aspects of many of these reactions have been explained ${ }^{2}$. Chloramine-T [CAT] is a strong electrolyte stable in aqueous solution and has been extensively used as an oxidant and synthetic reagent ${ }^{3}$. Chloramine-T acts as an oxidizing agent in both acidic and alkaline media ${ }^{4,5}$. The redox potential ${ }^{6,7}$ of chloramine-T/RNH${ }_{2}$ (where $\mathrm{RNH}_{2}$, the reduction product of chloramine- $\mathrm{T}$ is $p$-toluene sulphonamide) is $\mathrm{pH}$ dependent and decreases with increases in $\mathrm{pH}$ of the medium. Generally, chloramine- $\mathrm{T}$ (CAT or RNCINa, where $\mathrm{R}=\mathrm{CH}_{3} \mathrm{C}_{6} \mathrm{H}_{4} \mathrm{SO}_{2}$ ) undergoes a two electron change in its reaction. Depending on $\mathrm{pH}$ of the medium, CAT furnishes different types of reactive species in solution such as $\mathrm{RNHCl}, \mathrm{RNCl}_{2}, \mathrm{HOCl}$ and possibly $\mathrm{H}_{2} \mathrm{OCl}^{+}$in acid solutions and $\mathrm{RNCl}^{-}$and $\mathrm{OCl}^{-}$ions in alkaline medium ${ }^{8}$.

The potent oxidant is of special interest for studying reaction mechanism as it behaves as both a chlorinating and oxidizing agent ${ }^{9}$. It has been used widely for the quantitative direct and indirect determination of a large number of inorganic and organic compounds ${ }^{10}$. Although kinetic species of uncatalysed reaction involving CAT as oxidant ${ }^{11-15}$ have been made but few kinetic studies of catalysed CAT oxidations are reported $^{16-20}$.

Oxidation of $p$-hydroxy benzoic acid is of great importance from a chemical point of view. $p$-Hydroxy benzoic acid is used in the synthesis of dyes and many esters of ( $p$-HBA) have antiseptic properties.

The catalysis by transition metal ions in redox reactions is of immense interest ${ }^{21}$ and it plays an important role in understanding the mechanism of redox reactions. Their oxidizing and catalytic properties are due to the existence of variable oxidation states, as a consequence of partly filled $d$ or $f$ orbitals. Their ability to form both $\sigma$ and $\pi$ bonds with other moieties or ligands is one of the chief factors for imparting catalytic properties to transition metals as well as their complexes. Most of the $d$-block elements show characteristic interligand migration reactions and such a process forms one of the most important type of reactions in homogeneous catalysis. Ruthenium(III) chloride has been widely used as a homogeneous catalyst in various redox reactions ${ }^{22}$. The utility of ruthenium(III) chloride as a non-toxic and homogeneous catalytic has been reported by several workers ${ }^{23}$. The mechanism of catalysis is quite complicated due to the formation of different intermediate complexes, free radicals and different oxidizing states of $\mathrm{Ru}(\mathrm{III})$.

There are few reports on the kinetics of oxidation of $p$ hydroxy benzoic acid by CAT but least attention has been focused on CAT reaction with $p$-hydroxy benzoic acid acid 
using $\mathrm{Ru}(\mathrm{III})$ as catalyst particularly in acidic medium. So, this prompted us to investigate the systematic kinetic study of the oxidation of $p$-hydroxy benzoic acid by ruthenium(III) chloride in acidic medium.

\section{EXPERIMENTAL}

The reagents employed were $p$-hydroxy benzoic acid (E. Merck), ruthenium chloride (Johnson \& Matthey) and chloramine-T (E. Merck). All other reagents were of A.R. grade. All solutions of the reagents were prepared in doubly distilled water. The prepared solution of chloramine-T was standardized iodometrically. The stock solution of $p$-hydroxy benzoic acid was prepared by dissolving the appropriate amount of it in known volume of distilled water and standarized against the standard solution of sodium hydroxide. In order to prevent any photochemical decomposition, the solution of chloramine$\mathrm{T}$ was stored in black coated bottles. The reaction bottles were also coated black from outside to avoid any photochemical effect. Perchloric acid (E. Merck) was used as a source of hydrogen ions and its solution were prepared in doubly distilled water.

Appropriate amounts of reactant were taken in a one vessel blackened outside and in another CAT which thermostated at the desired temperature $\left( \pm 0.1^{\circ} \mathrm{C}\right)$. The reaction was initiated by rapidly adding a required amount of CAT solution to the reaction mixture. Aliquots $(10 \mathrm{~mL}$ each) of the reaction mixture were withdrawn at regular time intervals and unconsumed amount of CAT were determined iodometrically, using starch as an indicator. The rate of reaction $(-\mathrm{dc} / \mathrm{dt})$ in each kinetic run was calculated with the help of the slope of the tangent drawn at fixed [chloramine-T] in the plot of unconsumed [chloramine-T] vs. time. The order of reaction with respect to each reactants was calculated by the relationship between the initial rate $(-\mathrm{dc} / \mathrm{dt})$ and concentration of each reactants.

Varying ratios of [CAT] and $p$-HBA under the condition of $[\mathrm{CAT}]>>$ [Substrate] were equilibrated at room temperature for $48 \mathrm{~h}$. Estimation of unreacted CAT, showed that in the oxidation of $p$-HBA only one mole of chloramine-T was consumed. The observed stoichiometry may be represented as -

$$
\begin{array}{ccc}
\mathrm{C}_{6} \mathrm{H}_{4}(\mathrm{OH}) \mathrm{COOH}+\underset{\mathrm{CH}_{3} \mathrm{C}_{6} \mathrm{H}_{4} \mathrm{SO}_{2} \mathrm{NClNa}}{\mathrm{NCH}_{2} \mathrm{O} \rightarrow} \\
& (\mathrm{CAT}) & \mathrm{CH}_{3} \mathrm{C}_{6} \mathrm{H}_{4} \mathrm{SO}_{2} \mathrm{NH}_{2}+\mathrm{Na}^{+}+\mathrm{Cl}^{-} \\
& +\mathrm{C}_{6} \mathrm{H}_{4}(\mathrm{OH})_{2}+\mathrm{CO}_{2}
\end{array}
$$

where $\mathrm{C}_{6} \mathrm{H}_{4}(\mathrm{OH}) \mathrm{COOH}$ represents $p$-hydroxy benzoic acid while $\mathrm{C}_{6} \mathrm{H}_{4}(\mathrm{OH})_{2}$ represents reaction product as quinol which was detected and estimated gravimetrically as well as by TLC ${ }^{24}$.

\section{RESULTS AND DISCUSSION}

The reaction was studied at several initial concentrations of the reactants and the kinetic results were reported in Table-1. The rate of reaction-dc/dt increases linearly on the increasing concentration of CAT. The value of initial rate $(-\mathrm{dc} / \mathrm{dt})$ in each kinetic run was calculated from the slope of the plot of unconsumed [CAT] versus time at fixed [CAT], which is labelled as [CAT]*. The value of first order rate constant $\left(\mathrm{k}_{\mathrm{obs}}\right)$ in each kinetic run was calculated as:

$$
\mathrm{k}_{\mathrm{obs}}=\frac{(-\mathrm{dc} / \mathrm{dt})}{(\mathrm{CAT})}
$$

The value of rate constant approximately same to each other at different concentration of CAT (Table-1) showing first order depedence with respect to CAT. The first order rate

\begin{tabular}{|c|c|c|c|}
\hline \multicolumn{4}{|c|}{$\begin{array}{c}\text { TABLE-1 } \\
\text { EFFECT OF VARIATION OF [CAT }],[p \text {-HBA] AND } \\
{[\mathrm{Ru}(\mathrm{III})] \text { ON THE RATE OF REACTION AT } 35^{\circ} \mathrm{C}}\end{array}$} \\
\hline $\begin{array}{c}{[\mathrm{CAT}] \times 10^{4}} \\
\left(\mathrm{~mol} \mathrm{dm}^{-3}\right)\end{array}$ & $\begin{array}{c}{[p-\mathrm{HBA}] \times 10^{3}} \\
\left(\mathrm{~mol} \mathrm{dm}^{-3}\right)\end{array}$ & $\begin{array}{c}{[\mathrm{Ru}(\mathrm{III})] \times 10^{6}} \\
\left(\mathrm{~mol} \mathrm{dm}^{-3}\right)\end{array}$ & $\begin{array}{c}\mathrm{k}_{\mathrm{obs}} \times 10^{4} \\
\left(\mathrm{~s}^{-1}\right)\end{array}$ \\
\hline 1.50 & 3.00 & 1.00 & 2.75 \\
\hline 2.00 & 3.00 & 1.00 & 2.78 \\
\hline 2.50 & 3.00 & 1.00 & 2.99 \\
\hline 3.00 & 3.00 & 1.00 & 2.78 \\
\hline 3.50 & 3.00 & 1.00 & 2.76 \\
\hline 1.00 & 1.50 & 1.00 & 1.68 \\
\hline 1.00 & 2.00 & 1.00 & 2.19 \\
\hline 1.00 & 2.50 & 1.00 & 2.84 \\
\hline 1.00 & 3.00 & 1.00 & 3.27 \\
\hline 1.00 & 3.50 & 1.00 & 3.93 \\
\hline 1.00 & 3.00 & 1.50 & 2.38 \\
\hline 1.00 & 3.00 & 2.00 & 3.15 \\
\hline 1.00 & 3.00 & 2.50 & 4.08 \\
\hline 1.00 & 3.00 & 3.00 & 4.68 \\
\hline 1.00 & 3.00 & 3.50 & 5.56 \\
\hline
\end{tabular}
constant $\left(\mathrm{k}_{\mathrm{obs}}\right)$ increases linearly with increase in both $(p$-HBA) and $\mathrm{Ru}(\mathrm{III})$ under the experimental condition (Table-1).

TABLE-1

Table- 2 comprises the data showing the effect of variation

\begin{tabular}{|c|c|c|c|}
\hline \multicolumn{4}{|c|}{$\begin{array}{l}\text { TABLE-2 } \\
\text { EFFECT OF VARIATION OF }\left[\mathrm{H}^{+}\right],\left[\mathrm{Cl}^{-}\right] \text {AND ADDITION } \\
\text { OF [PTS] ON THE RATE OF REACTION AT } 35^{\circ} \mathrm{C}\end{array}$} \\
\hline $\begin{array}{l}{\left[\mathrm{H}^{+}\right] \times 10^{2}} \\
\left(\mathrm{~mol} \mathrm{dm}^{-3}\right)\end{array}$ & $\begin{array}{l}{[\mathrm{KCl}] \times 10^{3}} \\
\left(\mathrm{~mol} \mathrm{dm}^{-3}\right)\end{array}$ & $\begin{array}{c}{[\mathrm{PTS}] \times 10^{3}} \\
\left(\mathrm{~mol} \mathrm{dm}^{-3}\right)\end{array}$ & $\begin{array}{c}\mathrm{k}_{\mathrm{obs}} \times 10^{4} \\
\left(\mathrm{~s}^{-1}\right)\end{array}$ \\
\hline 5.00 & 1.00 & - & 2.98 \\
\hline 6.00 & 1.00 & - & 2.65 \\
\hline 7.00 & 1.00 & - & 2.39 \\
\hline 8.00 & 1.00 & - & 2.12 \\
\hline 9.00 & 1.00 & - & 1.78 \\
\hline 5.00 & 0.00 & - & 2.16 \\
\hline 5.00 & 1.00 & - & 2.19 \\
\hline 5.00 & 1.50 & - & 2.15 \\
\hline 5.00 & 2.00 & - & 2.16 \\
\hline 5.00 & 2.50 & - & 2.10 \\
\hline 5.00 & 3.00 & - & 2.13 \\
\hline 5.00 & 3.50 & - & 2.18 \\
\hline 5.00 & 1.00 & 0.00 & $3.33^{*}$ \\
\hline 5.00 & 1.00 & 1.00 & $3.53^{*}$ \\
\hline 5.00 & 1.00 & 2.00 & $3.46^{*}$ \\
\hline 5.00 & 1.00 & 3.00 & $3.15^{*}$ \\
\hline 5.00 & 1.00 & 4.00 & $3.87^{*}$ \\
\hline 5.00 & 1.00 & 5.00 & $3.27^{*}$ \\
\hline 5.00 & 1.00 & 6.00 & $3.36^{*}$ \\
\hline $4.00^{\mathrm{a}}$ & 1.00 & - & 2.80 \\
\hline $4.00^{b}$ & 1.00 & - & 6.47 \\
\hline $4.00^{c}$ & 1.00 & - & 11.20 \\
\hline \multicolumn{4}{|c|}{$\begin{array}{l}\text { Under the condition of }[\mathrm{CAT}]=1.00 \times 10^{-4} \mathrm{~mol} \mathrm{dm}^{-3} ;[p-\mathrm{HBA}]=3 \times \\
10^{-3} \mathrm{~mol} \mathrm{dm}^{-3} ;[\mathrm{Ru}(\mathrm{III})]=1 \times 10^{-6} \mathrm{~mol} \mathrm{dm} \mathrm{dm}^{-3} ;[p-\mathrm{HBA}]=2.50 \times 10^{-3} \mathrm{~mol} \\
\mathrm{dm}^{-3} ;\left[\text { PTS Variation); Temp, } 30^{\circ}(\mathrm{a}), 40^{\circ}(\mathrm{b}), 45^{\circ}(\mathrm{c})\right.\end{array}$} \\
\hline
\end{tabular}
of $\left[\mathrm{H}^{+}\right]$and addition of potassium chloride and $p$-toluene sulphonamide (PTS). The rate constant decreases with an increase in $\left[\mathrm{HClO}_{4}\right]$ showing inverse first order effect of $\left[\mathrm{H}^{+}\right]$ 
variation in its concentration range $5 \times 10^{-2}$ to $9 \times 10^{-2} \mathrm{~mol} \mathrm{dm}^{-3}$. A negative $\left[\mathrm{Cl}^{-}\right]$effect was observed. Addition of PTS did not influence the rate. this is also evident from nearly constant $\mathrm{k}_{\mathrm{obs}}$ values at different PTS. Variation of ionic strength (I) from $2 \times 10^{-2}$ to $5.50 \times 10^{-2} \mathrm{~mol} \mathrm{dm}^{-3}$ shows negligible effect on rate of reaction. The reaction was studied in $30-40{ }^{\circ} \mathrm{C}$ temperature range and free energy of activation $\left(\Delta \mathrm{G}^{*}\right)$ calculated from the rate measurements at these temperatures are given in Table-3.

\begin{tabular}{|c|c|}
\hline \multicolumn{2}{|c|}{$\begin{array}{c}\text { TABLE-3 } \\
\text { ACTIVATION PARAMETERS OF [Ru(III)] CATALYZED } \\
\text { OXIDATION OF [p-HBA] BY [RN NaCl] IN ACIDIC MEDIUM } \\
\text { UNDER THE CONDITION OF TABLES } 1 \text { AND } 2 \text { AT } 35^{\circ} \mathrm{C}\end{array}$} \\
\hline Parameters & Values \\
\hline $\mathrm{Ea}\left(\mathrm{kJ} \mathrm{mol}^{-1}\right)$ & 73.68 \\
\hline$\Delta \mathrm{S}^{\#}\left(\mathrm{JK}^{-1} \mathrm{~mol}^{-1}\right)$ & -17.42 \\
\hline$\Delta \mathrm{H}^{\#}\left(\mathrm{~kJ} \mathrm{~mol}^{-1}\right)$ & 71.12 \\
\hline$\Delta \mathrm{G}^{\#}\left(\mathrm{~kJ} \mathrm{~mol}^{-1}\right)$ & 76.49 \\
\hline $\mathrm{A} \times 10^{-13}\left(\mathrm{~mol}^{-1} \mathrm{dm}^{3} \mathrm{~s}^{-1}\right)$ & 9.18 \\
\hline
\end{tabular}

Chloramine-T behaves like a strong electrolyte ${ }^{25}$ and ionizes in aqueous solutions as follows:

$$
\mathrm{RN} \mathrm{NaCl} \rightleftharpoons \mathrm{RNCl}^{-}+\mathrm{Na}^{+}
$$

where $\mathrm{R}=\mathrm{CH}_{3} \mathrm{C}_{6} \mathrm{H}_{4} \mathrm{SO}_{2}$

Chloramine- $\mathrm{T}$ in acidic medium exists as following equilibria-

$$
\begin{aligned}
& 2 \mathrm{RN} \mathrm{HCl} \rightleftharpoons \mathrm{RNCl}_{2}+\mathrm{RNH}_{2} \\
& \mathrm{RNCl}_{2}+\mathrm{H}_{2} \mathrm{O} \rightleftharpoons \mathrm{RNHCl} \mathrm{HOCl} \\
& \mathrm{RNHCl}+\mathrm{H}_{2} \mathrm{O} \rightleftharpoons \mathrm{RNH}_{2}+\mathrm{HOCl}
\end{aligned}
$$

Thus in the acidified solution of chloramine-T, the possible oxidizing species are $\mathrm{RNHCl}, \mathrm{RNCl}_{2}, \mathrm{HOCl}$ and $\mathrm{CAT}$ as such. If $\mathrm{RNCl}_{2}$ were to be reactive species, the rate law would require second order depedence on CAT, which is contrary to the experimental observations. If $\mathrm{HOCl}$ was to be reactive species, a first order retardation of the rate by added para-toluene sulphonamide would be expected which is again contrary to the observed zero effect.

Further if $\mathrm{RNHCl}$ was to be reactive species, then fractional order with respect to (PTS) would be required which is also contrary to observed zero effect of (PTS). Hence CAT itself may be taken as real reactive species of chloramine-T.

Ruthenium(III) chloride is reported ${ }^{26,27}$ to exist as $\left[\mathrm{RuCl}_{6}\right]^{3-}$ in acidic medium. Ruthenium(III) chloride exist as $\left[\mathrm{Ru}\left(\mathrm{H}_{2} \mathrm{O}\right)_{6}\right]^{3+}$ in dil. $\mathrm{HCl}^{28}$. Such type of aqueous complexes are known to exist in the form of $\left[\mathrm{Ru}\left(\mathrm{H}_{2} \mathrm{O}\right)_{5} \mathrm{OH}\right]^{2+}$ in equilibrium ${ }^{29}$ with hexa aquo form.

$$
\left[\mathrm{Ru}\left(\mathrm{H}_{2} \mathrm{O}\right)_{6}\right]^{3+} \rightleftharpoons\left[\mathrm{Ru}\left(\mathrm{H}_{2} \mathrm{O}\right)_{5} \mathrm{OH}\right]^{2+}+\mathrm{H}^{+}
$$

$\left[\mathrm{RuCl}_{6}\right]^{3-}$ which is in equilibrium with $\left[\mathrm{Ru}\left(\mathrm{H}_{2} \mathrm{O}\right)_{5} \mathrm{OH}\right]^{2+}$ in the following manner ${ }^{30}$.

$$
\left[\mathrm{RuCl}_{6}\right]^{3+}+\mathrm{H}_{2} \mathrm{O} \rightleftharpoons\left[\mathrm{RuCl}_{5} \cdot \mathrm{H}_{2} \mathrm{O}\right]
$$

This equilibrium in right direction would be highly favoured in acidic medium, hence $\left[\mathrm{RuCl}_{5} \cdot \mathrm{H}_{2} \mathrm{O}\right]^{2+}$ has been taken as real effective catalytic species in acidic medium.

Considering the reactive species of chloramine- $T$ and $\mathrm{RuCl}_{3}$ in aqueous acidic medium as well as the observed kinetic results, the following reaction scheme is suggested.

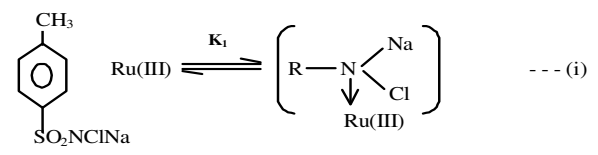

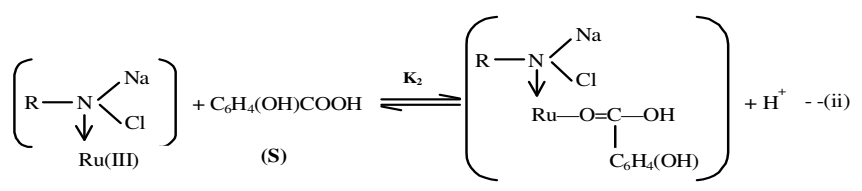

$$
\begin{aligned}
& \text { (X) } \\
& \mathrm{X}+\mathrm{H}_{2} \mathrm{O} \underset{\text { Slow }}{\stackrel{\mathrm{k}}{\longrightarrow}} \mathrm{CH}_{3} \mathrm{C}_{6} \mathrm{H}_{4} \mathrm{SO}_{2} \mathrm{NH}_{2}+\mathrm{CO}_{2}+\mathrm{Ru}(\mathrm{III})+ \\
& \mathrm{C}_{6} \mathrm{H}_{4}(\mathrm{OH})_{2}+\mathrm{NaCl}
\end{aligned}
$$

The reaction scheme of above chemical reaction in which oxidant chloramine-T first interact with catalyst $\mathrm{Ru}(\mathrm{III})$ and form complex $\left(\mathrm{C}_{1}\right)$. Then complex $\left(\mathrm{C}_{1}\right)$ react with $p$-hydroxy benzoic acid to form intermediate $(\mathrm{X})$ with the removal of $\mathrm{H}^{+}$. Finally intermediate $(\mathrm{X})$ with $\mathrm{H}_{2} \mathrm{O}$ give product and catalyst $\mathrm{Ru}(\mathrm{III})$ regenerate. Step (iii) is slow and rate determining step. In the light of aforesaid reaction scheme, the rate of reaction may be written in terms of rate of loss of [Chloramine-T] as eqn 1 .

$$
-\frac{\mathrm{d}[\mathrm{CAT}]}{\mathrm{dt}}=\mathrm{k}[\mathrm{X}]
$$

From step (1), we have

$$
\mathrm{K}_{1}=\frac{\left[\mathrm{C}_{1}\right]}{[\mathrm{CAT}][\mathrm{Ru}(\mathrm{III})]}
$$

From step (2), we have

$$
\begin{aligned}
\mathrm{K}_{2} & =\frac{[\mathrm{X}]\left[\mathrm{H}^{+}\right]}{\left[\mathrm{C}_{1}\right][\mathrm{S}]} \\
{[\mathrm{X}] } & =\frac{\mathrm{K}_{2}\left[\mathrm{C}_{1}\right][\mathrm{S}]}{\left[\mathrm{H}^{+}\right]}
\end{aligned}
$$

where $\mathrm{S}=p$-hydroxy benzoic acid. By comparing eqns 2 and 3 , we have

$$
[\mathrm{X}]=\frac{\mathrm{K}_{1} \mathrm{~K}_{2}[\mathrm{CAT}][\mathrm{Ru}(\mathrm{III})][\mathrm{S}]}{\left[\mathrm{H}^{+}\right]}
$$

On substituting the value of $[\mathrm{X}]$ from eqn 4 in eqn 1 , we have eqn 5 .

$$
-\frac{\mathrm{d}[\mathrm{CAT}]}{\mathrm{dt}}=\frac{\mathrm{kK}_{1} \mathrm{~K}_{2}[\mathrm{CAT}][\mathrm{Ru}(\mathrm{III})][\mathrm{S}]}{\left[\mathrm{H}^{+}\right]}
$$

The rate expression eqn 5 fully explains all observed kinetic data. It explains first order kinetics with respect to oxidant, first order with respect to substrate, first order with respect to catalyst and inverse first order kinetics with respect to $\left[\mathrm{H}^{+}\right]$i.e. medium. Thus, the mechanism seems to be valid.

\section{REFERENCES}

1. H.S. Singh, A.K. Sisodia, S.M. Singh, R.K. Singh and R.N. Singh, J. Chim. Phys. Phys.-Chim. Biol., 73, 283 (1976).

2. Puttaswamy and N. Vaz, J. Chem. Sci.., 113, 325 (2001).

3. D.H. Bremner, in ed.: J.S. Pized, Synthetic Reagents, Ellish Horwood Limited, England, vol. 6 (1985).

4. S.P. Mushran, R.M. Mehrotra and R. Sanehi, J. Indian Chem. Soc., 51, 594 (1974).

5. A. Kumar and R.A. Singh, J. Indian Chem. Soc., 89, 1671 (2012).

6. A. Berka, J. Vulterin and J. Zyka, Newer Redox Titrants, Pergamon Press, Elmsford, New York, vol. 1, p. 37 (1965). 
7. D.S. Mahadevappa, K.S. Rangappa, N.M.M. Gowda and B.T. Gowda, J. Phys. Chem., 85, 3651 (1981).

8. P.S. Radhakrishnamurti and M.D.P. Rao, J. Indian Chem. Soc., 54, 1048 (1977).

9. K.S. Rangappa, H. Manjunathaswamy, M.P. Raghavendra and D.C. Gowda, Carbohydr. Res., 307, 253 (1998).

10. I.M. Kolthoff and R. Belcher, Volumetric Analysis, Interscience, New York, edn 3 (1957).

11. T. Higuchi and A. Hussain, J. Chem. Soc. B, 549 (1967) and references cited therein.

12. D.S. Mahadevappa, M.B. Jadhav and H.M.K. Naidu, Int. J. Chem. Kinet., 11, 261 (1979).

13. A.K. Bose, R.M. Mehrotra and S.P. Mushran, Indian J. Chem., 17A, 896 (1973).

14. D.S. Mahadevappa, S. Ananda, N.M.M. Gowda and K.S. Rangappa, J. Chem. Soc. Perkin Trans. II, 39 (1985).

15. B. Singh, A.K. Samant and B.B.L. Saxena, Tetrahedran, 38, 2591 (1982).

16. A.C. Singh, A.K. Singh and B. Singh, Indian J. Chem., 44A, 476 (2005).

17. Ashish, A.K. Singh, A.K. Singh and B. Singh, Indian J. Chem., 43A, 1645 (2004).

18. A. Shukla and S.K. Upadhaya, J. Indian Chem., 30A, 154 (1991).

19. B. Singh, R. Dubey, K. Lata Singh and A.K. Singh, Int. J. Pure Appl.
Chem., 5, 119 (2010).

20. Ashish, S.P. Singh, A.K. Singh and B. Singh, J. Mol. Catal. Chem., 266, 226 (2007).

21. K.R. Bhat, K. Jyothi and B. Gowda Thimme, Oxid. Commun., 25, 117 (2002).

22. S.H. Srivastava, K. Singh, M. Shukla and N. Pandey, Oxid. Commun., 24, 558 (2001).

23. S. Srivastava, K. Singh, A. Awasthi and H. Tripathi, Oxid. Commun., 24, 388 (2001).

24. A.I. Vogel, In Quantitative Organic Analysis (Part-3), ELBS, Longmann, London, p. 739 (1958).

25. E. Bishop and V.J. Jennings, Talanta, 1, 197 (1958).

26. J. Emsley, The Elements (Oxford Chemistry Guides), Oxford University Press, edn 3 (1998).

27. H.H. Cady and R.E. Connick, J. Am. Chem. Soc., 80, 2646 (1958).

28. J.C. Bailar, H.J. Emeleus, R.S. Nyholm and A.F. Trotman-Dickenson, Comprehensive Inorganic Chemistry, Pergamon, Oxford, edn 1, Vol. 3, p. 1193 (1973).

29. F.A. Cotton and G. Wilkinson, Advanced Inorganic Chemistry, Wiley, New York, edn 2, p. 152 (1966).

30. R.E. Connick and D.A. Fine, J. Am. Chem. Soc., 83, 3414 (1961). 